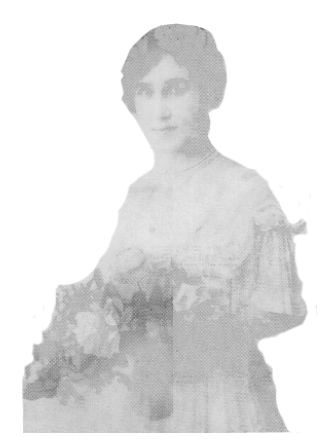

\title{
GÊNERO E CIDADANIA: REFERENCIAIS ANALÍTICOS
}

\author{
MARIA NOEMI CASTILHOS BRITO
}

\begin{abstract}
Resumo: Os temas propostos neste trabalho - cidadania e gênero - levam-nos a buscar referenciais de análise suficientemente abrangentes para que possamos dar conta da sua articulação. A idéia de cidadania e a construção de identidade de gênero têm sido definidas como um entendimento da sociedade que parte da definição de esferas dicotômicas, o público e o privado, responsáveis por uma desqualificação das mulheres no âmbito do político. O feminismo contemporâneo discute esta visão, criticando-a, e propõe novas abordagens que permitem integrar homens e mulheres nas suas relações, no desenvolvimento dos processos sociais.

Palavras chaves: gênero, cidadania, participação feminina.
\end{abstract}

Os temas propostos neste trabalho - cidadania e gênero - nos levam a buscar referenciais de análise suficientemente abrangentes para que possamos dar conta da sua articulação.

Os gregos conceberam a idéia de cidadania como um atributo de homens livres, que seriam as pessoas aptas para as atividades políticas, ficando as mulheres, os servos e os escravos relegados a um lugar à margem dos assuntos de interesse público. Historicamente, a construção das identidades de homens e mulheres se tem configurado a partir da dicotomia entre as esferas pública e privada, com atribuições de papéis, atitudes e valores previamente definidos segundo modelos naturais.

A partir da década de 70, com o desenvolvimento do movimento feminista, tece-se uma crítica às concepções vigentes de rígida separação das esferas 


\section{GÊNERO E CIDADANIA: REFERENCIAIS ANALÍTICOS}

acima referidas segundo características "inerentes" aos sexos. Trata-se de mostrar que esta discussão não pode ser abstraída do seu contexto histórico liberal. ${ }^{1}$

O feminismo contemporâneo, através da crítica à rigidez das oposições binárias como categorias explicativas, tem buscado referenciais de análise menos limitados, os quais permitam integrar homens e mulheres nas suas relações, no desenvolvimento dos processos sociais. Nesta linha, Scott apresenta urna importante contribuição ao debate ao propor o uso do gênero como categoria de análise a partir de uma definição abrangente pela qual é possível compreender a relações entre gêneros e a constituição da sociedade, onde se inclui necessariamente a dimensão política.

A partir da perspectiva de gênero, têm sido priorizadas as investigações históricas e sociológicas que procurem incorporar as dimensões do masculino e do feminino na análise de forma relacional. Estas investigações buscam compreender a interação entre masculino e feminino na totalidade da vida social, contrariando enfoques da ciência política que incompatibilizavam a mulheres com a vida política ou pública através explicações que partiam de equações como: Homem = Público, Público = Político, logo, Homem Político; e Mulher = Privado, Privado $=$ Apolítico, logo, Mulher Apolíica .

Os dados levantados em pesquisas de historiadoras e antropólogas têm mostrado experiências femininas que não podem ser interpretadas a partir de definições dicotômicas, preestabelecidas. A emergência de tais dados conduziu ao reexaminar conceitos e critérios sobre as relações entre o privado e o público, bem como entre o pessoal e o político, na busca de novas alternativas de análise.

As novas abordagens que vêm sendo desenvolvidas partir das indagações feministas têm dado visibilidade à presença de mulheres como agentes integrados aos processos sociais, e justamente por isto têm despertado inquietações teóricas em várias áreas das ciências humanas. Os dados levantados nas investigações sobre a experiência concreta das mulheres em sociedade, dados que vêm sendo levantados principalmente pela história, pela antropologia e pela sociologia, evidenciam que as atividades femininas se têm desenvolvido também em espaços públicos como a comunidade, a vizinhança, a rua e a fábrica, e não podem ser considerados como exclusivamente privadas, pois envolvem intermediações e relações múltiplas de difícil enquadramento em pólos dicotômicos. Várias pesquisadoras responsáveis por estes trabalhos têm enfatizado a necessidade serem repensados conceitos ideológicos enraizados e tidos como explicativos e, principalmente, de "reavaliar o político no campo da história social do dia-a-dia". Proposta semelhante aparece nos textos assinados por Perrot, que considera importante interrogar-se sobre as práticas de poder, as imbricações, as redistribuições a agir na sociedade e sobre a especificidade do político. ${ }^{2}$

'PATEMAN, 1983.

2 PERROT, 1986, p. 85. 
Scott, analisando o conceito de gênero, refere-se à política e ao poder como territórios praticamente inexplorados, na medida em que a história política "foi o bastião da resistência à inclusão de materiais ou questões sobre as mulheres e o gênero". ${ }^{3}$ As perspectivas abertas por estas autoras sugerem que se reveja uma definição do político como domínio exclusivamente masculino, e se analisem as formas pelas quais a população feminina tem conseguido expressar-se politicamente em determinados contextos históricos.

A relação entre as mulheres e a vida política, embora considerada como um fato inexpressivo pela maioria dos cientistas sociais, foi examinada de forma intensiva em estudo pioneiro de Maurice Duverger (1955), promovido pela Unesco, que concluía pela disparidade observada entre a participação das mulheres nas eleições e no círculo governamental. No plano eleitoral, a participação feminina era importante, não tendo sido encontradas diferenças de comportamento significativas entre mulheres e homens. Já no plano governamental, a situação é diferente, verificando-se uma participação feminina fraca e retraída.

Nos anos 50 e 60, este trabalho serviu de referência básica a interpretações calcadas em análises de dados de comportamento eleitoral, participação partidária, representação parlamentar e sondagens de opinião, que enfatizavam a imagem da mulher dedicada ao lar e afastada do mundo da políica. Reforçava-se, assim, o consenso tradicional da mulher pertencente ao domínio familiar e privado, e do homem ligado ao domínio da atividade pública, na qual se inclui a participação política.

Tal enfoque, entretanto, tem sido criticado por trabalhos que propõem um reexame crítico destes referenciais e um levantamento das distorções encontradas, na medida em que tais pressupostos se apoiam na aceitação dos modelos masculinos de práticas políticas que se refletem na própria coleta de dados e na sua posterior análise.

As informações levantadas em diversas pesquisas, desenvolvidas principalmente nos Estados Unidos, propiciaram uma ampla discussão entre cientistas políticas feministas que enfatizavam a necessidade de superar a visão das mulheres como essencial e naturalmente apolíticas, buscando novos referenciais teóricos para analisar o comportamento político feminino. Pode-se considerar como ponto básico deste debate as propostas de reconceitualização do político quanto à sua natureza e ao seu âmbito. A ampliação do conceito levou não só a que se considerassem políticos temas tidos como privados, mas a que se fosse além das definições centradas na competição pelo poder, destacando-se a necessidade de se olhar mais atentamente para a política do cotidiano, a micropolítica. Desta forma, seria possível perceber as práticas políticas diferentes do padrão masculino, investigando os canais por meio dos quais as mulheres se manifestariam. ${ }^{4}$

${ }^{3}$ SCOT, 1990, p. 18.

${ }^{4}$ GUIVANT, s/d, p. I8-9. 


\section{GÊNERO E CIDADANIA: REFERENCIAIS ANALÍTICOS}

Neste sentido, o mais importante não seriam o aspectos quantitativos da participação política feminina. Haveria, antes, que tratar das questões levantadas pelo tipo de participação das mulheres no político, mostrando-se a existência social e políitica de um sujeito feminino no qual se reconhecesse um poder e que se movimenta, se empenha conforme a situação vivida em cada época. ${ }^{5}$ As redefinições conceptuais propostas pela crítica feminista alargaram as perspectivas de análise, reavaliando, através de exemplos de estratégias femininas exitosas, a pretensa invisibilidade e/ou marginalidade das mulheres na política.

Entretanto, na América Latina, incluindo-se aí o Brasil, a tendência predominante durante muito tempo foram estudos preocupados sobretudo em encontrar o porquê da ausência feminina do mundo da política, considerada especialmente do ponto de vista institucional. Contrariamente aos exemplos de trabalhos europeus e norte-americanos, interessados em reconstruir o passado submerso das mulheres, a pesquisa sobre a presença das mulheres latino-americanas na história só se desenvolveu quando elas emergiram como protagonistas na cena política dos seus países, a partir do final da década de 70.

As raras resenhas da produção acadêmica latino-americana sobre o tema mulher e política apresentam esta contraste. Ao destacarem as principais linhas trabalhadas na área, coincidem na avaliação de que - apesar da expansão das investigações sobre a questão feminina - permaneceram escassas as reflexões teóricas mais aprofundadas sobre o papel das mulheres no campo político.

Os limites teóricos apontados em muitos estudos prendem-se especialmente com o predomínio de duas linhas interpretativas: uma busca esclarecer os mecanismos de dominação responsáveis pela não-participação feminina, e outra apóia-se na dicotomia público-privado para distinguir os papéis femininos e masculinos em esferas distanciadas. $O$ uso destes referenciais de análise enfatiza o posicionamento subordinado da experiência feminina no privado e mesmo no estudo de várias situações nas quais as mulheres, a partir dos seus papéis de mãe e esposa, atuaram politicamente, considerando que se trata de um prolongamento do doméstico em momentos determinados da vida polííica.

No Brasil, partindo deste pressuposto, os estudos pioneiros na área da participação politico-partidária referem-se à "omissão" da mulher, ao "seu papel tradicionalmente passivo no acontecer político", e consideram que "o quadro é particularmente cinzento" baseando-se em dados numéricos dos processos eleitorais. ${ }^{6}$ As preocupações quantitativas "participacionistas", ${ }^{7}$ aliadas às dificuldades de obtenção de dados sobre o comportamento político-eleitoral, levaram os trabalhos que tinham como tema mulher e política a seguirem uma determinada linha de, por um lado, valorização da presença feminina na política institucional

${ }^{5}$ COHEN E GIORGIO, 1987, p. 9-19.

${ }^{\circ}$ TABAK E TOSCANO, 1982, p. 56-66

${ }^{7}$ GOLDBERG, 1989. 
(candidaturas, cargos eletivos e diretivos), e por outro de desqualificação de outras atividades das mulheres no âmbito político, mas fora do sistema proposto, o que dificulta outras possíveis abordagens. Mesmo quando as pesquisas empíricas indicam a presença feminina em espaços institucionais de representação - Câmara de Vereadores, Prefeituras ${ }^{8}$ — ou na ação política como grupo organizado — em defesa do civismo, como no golpe de $1964^{\circ}$ —, enfatiza-se o que seria o "caráter reflexo da ałuação feminina", ${ }^{10}$ ou seja, a obediência à influência familiar e/ou masculina nesta atuação.

Num dos primeiros trabalhos preocupados em compreender as relações entre a mulher e a política no Brasil, Blachman concluía pela limitada participação das mulheres brasileiras na política organizada, e apontava importantes questões ainda hoje não resolvidas satisfatoriamente. " Entre estas questões encontrase a parcialidade na seleção do material de pesquisa, ou seja, o entendimento da forma de fazer política identificada com os padrões masculinos, a omissão de dados históricos sobre a atividade política feminina, e a necessidade de se avaliar as relações existentes entre a família e a política.

Pesquisas voltadas para o questionamento da noção amplamente difundida de que as mulheres não têm atividade política têm buscado abordar outros âmbitos, além do contexto parlamentar de grandes centros urbanos, procurando "desvendar qual é o real espaço que é ocupado pela mulher na política brasileira" ${ }^{12}$ Com a atenção voltada para a dinâmica das relações sócio-políticas ao nível local, estas pesquisas ${ }^{13}$ contribuíram para identificar o exercício, por parte de mulheres, de atividades como agentes políticos - prefeitas ou vereadoras, professoras, benfeitoras, etc. -, mostrando as ligações entre família, religião, filantropia e a política partidária.

Mais recentemente, Avelar, também insatisfeita com os referenciais tradicionalmente empregados na análise da participação política feminina, se preocupou em analisar "a incorporação de um instrumento teórico que possibilite captar as formas singulares da participação das mulheres na vida política". ${ }^{14} \mathrm{~A}$ sua proposta enfatiza a necessidade de se levar em consideração as diferentes arenas de atuação política nas quais o ativismo feminino se expressa melhor, sem esquecer de considerar a família no processo através do qual as pessoas se envolvem politicamente.

De forma semelhante, num trabalho sobre a participação sócio-política de mulheres mexicanas, Tarrés propõe como referencial de análise a noção de campos

\footnotetext{
${ }^{8}$ COSTA, 1984 e 1986.

${ }^{9}$ SIMÕES, 1985.

${ }^{10}$ TABAK E TOSCANO, 1982, p. 25

"BLACHMAN, 1976, p. 138.

12 BLAY, s/d, p. 9.

${ }^{13}$ BLAY, s/d, e FELDMAN-BIANCO, 1976.

${ }^{14}$ AVELAR, 1987, p. 3.
} 


\section{GÊNERO E CIDADANIA: REFERENCIAIS ANALÍTICOS}

de ação. ${ }^{15}$ Esta noção refere-se ao controle feminino sobre diferentes áreas do espaço cotidiano, que influencia processos sociais e políticos mais gerais. Tratase de identificar aí uma forma distinta de fazer política, na qual sobressai a importância da participação das mulheres tanto nas mobilizações urbanas como nas atividades geradas a partir da prática religiosa. Este relevo vem a obstar à pouca visibilidade da participação das mulheres, na medida em que estas constituíram espaços de ação próprios que não são absorvidos nos conceitos das esferas pública ou privada.

A revisão teórica proposta por diversos autores na análise da participação política feminina, além da crítica ao viés androcêntrico, levanta como um ponto fundamental a ampliação do conceito de política, para que abarque não apenas a política institucional, mas também agregue atividades convencionais e não convencionais. ${ }^{16}$ Esta visão ampliada inclui ainda uma redefinição dos espaços de atuação das mulheres, mostrando as interpelações entre o público e o privado. Não se trata apenas da reivindicação feminista de politizar o privado, mas de considerar a mulher como um sujeito político, presente na esfera pública, através de espaços de visibilidade ${ }^{17}$ que podem ser os movimentos sociais, as campanhas e/ou os protestos políticos, os movimentos revolucionários ${ }^{18} \mathrm{e}$ até os próprios departamentos femininos nos partidos políticos. A política adquire então outras dimensões, mais amplas, abrangendo novas práticas significativas em outros níveis além do tradicional.

A idéia de um cotidiano feminino vivido no privado, isolado dos acontecimentos políticos e sociais, não encontra respaldo nas investigações empíricas, que, ao contrário, evidenciam relações que precisam ser analisadas a partir de novos referenciais. Certamente, a vida de muitas mulheres se constrói no espaço doméstico, mas este fato não pode ser entendido como sinônimo de isolamento e/ou conservadorismo. Debert, estudando a experiência de envelhecimento de mulheres de classe média em São Paulo, analisa depoimentos onde as entrevistadas, tidas como exclusivamente domésticas, demonstram conhecimento, interesse e entusiasmo pela política, o que leva a pesquisadora a questionar a redução da família ao privado entendido como apolítico. ${ }^{19}$

Blay, ao estudar o período de 1964 a 82 no Brasil, discute a conquista da cidadania pela mulher, aventando que os diversos movimentos com participação feminina, inclusive sindical, se constituem num conjunto que levou à apropriação do espaço público e à reformulação deste mesmo espaço. ${ }^{20}$ Ao lado das transformações individuais, pessoais, a nível do privado, se chega gradativamen-

\footnotetext{
${ }^{15}$ TARRÉS, 1989, p. 12.

${ }^{16}$ BAQUERO, 1981, p. 30

17 PINTO, 1990, p. 6.

${ }^{18}$ AVELAR, 1987, p. 24.

${ }^{19}$ DEBERT, 1984, p. 139-40,

${ }^{20}$ BLAY, 1982, p. 10.
} 
MARIA NOEMI CASTILHOS BRITO

te a transformações a nível público. Quando se considera a vivência de participação das mulheres nos movimentos populares, "politiza-se o privado, dá-se existência a uma experiência até então silenciada e, por este caminho, abre-se a possibilidade de pensar a mudança" ${ }^{21}$

As mulheres, portanto, mesmo partindo da esfera privada, podem agir politicamente, utilizando recursos específicos, seguindo caminhos que cruzam os espaços públicos e privados. A dimensão política não se restringe exclusivamente à esfera pública, às atividades masculinas, mas está presente também no cotidiano que homens e mulheres vivenciam em conjunto numa determinada relação histórica e que interessa analisar com um enfoque integrador, sem pré-interpretações globalizantes, sem juízos valorativos que desqualificam de antemão formas diferenciadas de envolvimento político.

As mulheres brasileiras, especialmente nas últimas décadas, das mais diversas formas, têm afirmado a sua cidadania, constituindo-se como sujeitos sociais através dos seus movimentos e ações, ligadas ou não a instituições políticas. Esta situação não é exclusivamente brasileira. Pelo contrário, a presença feminina nos processos de mudança sócio-política em países como Argentina, Uruguai, Chile, Peru, Bolívia, Nicarágua e outros mais, tem-se evidenciado de forma significativa, merecendo estudos e reflexões mais detidas. Ser mulher na América Latina hoje envolve a luta pelo reconhecimento da sua posição como sujeito social presente no contexto latino-americano, exigindo dos analistas da sociedade uma atenção especial que destaque a diferenciação por gênero.

${ }^{21}$ CALDEIRA, 1985, p. 35. 


\section{GÊNERO E CIDADANIA: REFERENCIAIS ANALÍTICOS}

\section{Referênclas blbllográficas}

AVELAR, Lúcia. "A participação política da mulher e a ideologia do conservadorismo político feminino: subsídios para novas pesquisas". XI Encontro Anual da ANPOCS, Águas de São Pedro, 1987 (mimeo).

BAQUERO, Marcelo. "Participação política na América Latina: problemas de conceituação". Revista Brasileira de Estudos Políticos, n. 57, 1981, p. 7-34.

BLACHMAN, Morris J. "Problemas encontrados en la investigación de la actividad política organizada de la mujer en Brasil". In: ENERO, Elu de, e CARMEN, Maria del (orgs.). Perspectivas femininas en America Latina. México: Sepsetentas, 1976, p. 125-49.

BLAY, Eva. As prefeitas. Rio de Janeiro: Avenir, s/d.

"Do espaço privado ao público: a conquista da cidadania pela mulher no Brasil". VI Encontro Anual da ANPOCS, Nova Friburgo, 1982 (mimeo).

CALDEIRA, Teresa. Mulheres, cotidiano e política. São Paulo: Cebrap, 1985 (mimeo).

COHEN, Yolande, e GIORGIO, Michela de. "Presentation". In: Cohen, Y. (dir.). Femme et contrepouvoirs. Montreal: Boreal, 1987, p. 9-20.

COSTA, Ana Alice. "A vereadora baiana e seu papel na vida política". VIII Encontro Anual da ANPOCS. São Paulo, 1984

COSTA. Ana Alice. "A participação política da mulher e a dominação patriarcal: uma introduÇão". X Encontro Anual da ANPOCS, Campos do Jordão, 1986 (mimeo).

DEBERT, Guita. "História de vida e experiência do envelhecimento para mulheres de classe média em São Paulo". Cadernos do Ceru, n. 19, junho de 1984, p. 26-47.

DUVERGER. Maurice. La participatión des femmes à la vie. Paris: Unesco, 1955

FELDMAN-BIANCO, Bela. "Sex, Class and Power: Women's Role in Brazilian Local Level Politics". VII National Meeting of the Latin American Studies Association, Atlanta, 1976 (mimeo).

GOLDBERG, Anette. "Feminismo no Brasil contemporâneo: o percurso intelectual de um ideário político". BIB, n. 28. Rio de Janeiro, 1989, p. 42-70.

GUIVANT, Júlia. "A ciência política e a questão feminina". Florianópolis: UFSC, s/d (mimeo).

PATEMAN, Carole. "Feminist Critiques of the Public/Private Dichotomy". In: BENN, S. I., e GAUS, G. F. (ed.). Public and Private and Social Life. London: Croom Helm, 1983, p. 281-303.

PERROT, Michelle. "Les femmes, le pouvoir, I'histoire". In: PERROT, M. (org.). Une histoire des femmes est-elle possible? Paris: Rivages, 1984, p. 205-22.

. "Histoire et pouvoir des femmes". In: AUBERT, N. et alli (orgs.). Le sexe du pouvoir. Paris: Desclée de Brouwer, 1986, p. 79-88.

PINTO, Céli Regina Jardim. "A trajetória da invisibilidade. A mulher enquanto objeto da ciência política". Seminário de Estudos Feministas FCC, São Roque, 1990 (mimeo).

SCOT, Joan. "Gênero: uma categoria útil de análise histórica". Educação e Realidade, v. 16, n. 2, 1990, p. 5-22.

SILTANEN, Janet, e STANWORTH, Michelle. "The Politics of Private Woman and Public Man". Theory and Society, v. 13, 1984, p. 91-118.

SIMÕES, Solange de Deus. As mulheres no go/pe de 1964. Petrópolis: Vozes, 1985.

TABAK, Fanny, e TOSCANO, Moema. Mulher e política. Rio de Janeiro: Paz e Terra, 1982.

TARRÉS, Maria Luisa. "Participación social y política de las mujeres: los campos de acción, una alternativa de análisis". XV Congresso Internacional da LASA, San Juan, Porto Rico, 1989 (mimeo).

Gender and Citizenship: Analytical References

Abstract: The themes proposed in this paper - gender and citizenship - lead us to seek analytical references wide enough to be able to think about how they are articulated. Concepts of citizenship and the construction of gender identity have been defined through an understanding of society based on the dichotomy of the private and public as responsible for disqualifying women from the public. Contemporary feminism discusses this viewpoint, criticizing it and proposing new approaches that permit the integration of men and women through their relationships in the development of social processes.

Keywords: gender, citizenship, women's participation 